\title{
Ball-Type Dioxy-o-Carborane Bridged Cobaltphthalocyanine: Synthesis, Characterization and DFT Studies For Dye-Sensitized Solar Cells as Photosensitizer
}

https://doi.org/10.1515/hc-2020-0007

Received October 30, 2019; accepted January 22, 2020.

\begin{abstract}
The synthesis and spectroscopic characterization of an innovative ball-type cobalt metallophthalocyanine 4, bridged by four 1,2-bis(2-hydroxymethyl)-O-carborane (HMOC) 1 units, has been achieved. The synthesized compound $\mathbf{4}$ was characterized structurally and electronically using elemental analysis, UV-Vis absorption spectroscopy, FT-IR spectroscopy, MALDI-TOF mass spectrometry, EPR spectroscopy and magnetic susceptibility. The photovoltaic performance of the newly synthesized compound in dye-sensitized solar cells was investigated. In order to clarify the effect of dye-sensitization time on photovoltaic performance parameters, the sensitization time was varied from 12 to $60 \mathrm{~h}$ and the performance parameters were investigated. It was found that sensitization time had a strong effect on the main performance parameters. The best photovoltaic performance was achieved after sensitization for $36 \mathrm{~h}$ (short circuit current density, $5.41 \mathrm{~mA}$ $\mathrm{cm}^{-2}$; overall conversion efficiency, 3.42\%). Computational UV-Vis absorption spectra of the molecule was calculated using time dependent density functional theory and was found consistent with measured UV-Vis spectra.
\end{abstract}

Keywords: metallophthalocyanine, carborane, photovoltaic, dye-sensitized solar cell, density functional theory

\section{Introduction}

Phthalocyanines (Pcs) are compounds that have an 18 $\pi$-electron system. This electron system provides Pcs with their unique conductometric, photophysical, and optoelectronic properties [1]. The photophysical and

\footnotetext{
* Corresponding author: Sevil Şener, Ege University, Aliaga Vocational School, 35800, İzmir-Turkey, e-mail: sevil.sener@ege.edu.tr, sevil.sesener@gmail.com
}

photochemical properties of Pcs can be controlled and modified using either the two general approaches or using a suitable combination: 1) varying the metal 2) the nature of the substituents in the peripheral or non-peripheral groups [2]. Any change in substituents depicts significant effects on various parameters for applications such as molecular electronic devices, non-linear optical devices, liquid crystals, gas sensors, photosensitizers, catalysts, semi-conductive materials, and electrochromic displays [3-8]. In this respect, the synthesis and electro-catalytic behaviour of metallophthalocyanine (MPc) derivatives have been extensively investigated [9]. Multi-nuclear MPcs with different linker groups have been extensively studied to be specifically used as highly efficient catalysts to perform electro-catalysis of the oxygen reduction reaction (ORR) and organic field effect transistors [10].

Ball-type Pcs, which is a new category of Pcs, were initially investigated in 2002 [11,12]. This new Pc-type depicts four bridging substituents on the peripheral positions of every benzene ring in the two co-facially arranged Pc monomers. The length between the two Pc rings and the resulting chemical and physical properties are dependent on the components of those linkers and depict a significant deviation from the initial monomers. The two face-to-face arranged Pc rings or the two metal centres are observed to interact strongly with each other in these compounds, and these interactions were detected spectroscopically and electrochemically. Based on the nature of the bridging compounds, the chemical and physical properties can change dramatically [13].

The synthesis of carboranyl derivatives is of considerable significance due to their similarity with some organic compounds that contain electron accepting groups [14,15]. Over the previous few decades, carbon-substituted carboranes have been investigated using new models by performing theoretical investigations [16], preparing organic and organometallic compounds that can be used to perform polymeric syntheses [17-19] and biological/ 
medicinal investigations [20]. Carbon-substituted carboranes have been effectively used for cancer treatment by boron neutron capture therapy (BNCT) [21-23].

Over the previous four decades, polyhedral heteroboranes have been extensively investigated. One of the members of this group of compounds are dicarbo-closododecaboranes, which are commonly named as carboranes. Carborane chemistry is especially concerned with $\mathrm{C}-\mathrm{H}$ or $\mathrm{B}-\mathrm{H}$ substitution reactions at the vertices of these clusters [15], and the reaction products may be potentially used in different applications, including medicinal chemistry, BNCT [24], polymer chemistry [25], adsorption/ extraction of metal ions [26], supramolecular chemistry [27] and as metal ligands.

After the work of M. Grätzel and co-workers [28], dye sensitized solar cells (DSSCs) have gained much attention as an alternative to traditional silicon-based photovoltaic devices. The working mechanism is based on a photoelectrochemical mechanism that resembles plant photosynthesis [29]. It is reported that one of the most important factors is the physicochemical properties of the dye molecule for the development of efficient DSSC $[30,31]$. Polypyridylruthenium complexes are reported to be the most successful charge-transfer sensitizers that are used in DSSC systems [32]. Although important advances have been made with polypyridylruthenium complexes toward high-performance solar cells, the Ru complexes have drawbacks such as the limited absorption wavelength [28]. Therefore, there is a strong need to develop new sensitizers with broader absorption profiles in the longer wavelength regions.

The present study reports a method for synthesizing a novel binuclear ball-type $\mathrm{M}_{2} \mathrm{Pc}_{2}, 4$ from commercial starting materials: 1,2-bis(2-hydroxymethyl)-o-carborane (HMOC) 1 and 4-nitrophthalonitrile 2. Binuclear ball-type metallophthalocyanine 4 was characterized spectroscopically and was then used to fabricate a DSSC.

\section{Results and discussion}

\section{Syntheses and compound characterization}

The synthesis of the target compound Co-Pc 4 is depicted in Scheme 1. The key starting material compound 3 could be obtained using a single step reaction of HMOC (1) and 4-nitrophthalonitrile (2) and could result in 35\% yield. Co-Pc 4 was readily obtained in $34.74 \%$ yield by the metal-templated cyclotetramerization of $\mathbf{3}$ with the metal salt $\mathrm{Co}(\mathrm{OAc})_{2}$.
Spectroscopic data of the newly synthesized compound was in agreement with the predicted structures in Scheme 1. Compound 3 was obtained in 35\% yield after work up. FT-IR Spectra of compounds $\mathbf{3}$ and $\mathbf{4}$ are given in Figure S1 and Figure S2, respectively. The IR spectrum of 3 confirms the presence of the $\mathrm{C} \equiv \mathrm{N}$ group as an intense and sharp stretching band at $2225 \mathrm{~cm}^{-1}$, and the typical $v(B-H)$ absorption frequency at $2533 \mathrm{~cm}^{-1}$ and $2366 \mathrm{~cm}^{-1}$ that is characteristic of closo-carboranes [33,34]. The characteristic $\mathrm{C}-\mathrm{O}-\mathrm{C}$ bridging group bands were observed at $1099 \mathrm{~cm}^{-1}$ for compound 3 and at $1095 \mathrm{~cm}^{-1}$ for compound 4. ${ }^{1} \mathrm{H}-\mathrm{NMR}$ and ${ }^{13} \mathrm{C}$-NMR Spectra of compound 3 are given in Figure $\mathrm{S} 3$ and Figure S4. In the ${ }^{1} \mathrm{H}-\mathrm{NMR}$ spectrum of 3, the aromatic protons appeared at 8.77 and $8.45 \mathrm{ppm}$ in the form of doublets, the phenyl proton appeared at $8.95 \mathrm{ppm}$ as a singlet, and the $\mathrm{C}-\mathrm{H}$ protons appeared at $3.11 \mathrm{ppm}$ as a singlet. The ${ }^{13} \mathrm{C}-\mathrm{NMR}$ spectrum of $\mathbf{3}$ shows signals in the aromatic carbons and nitrile carbons at 136.47, 129.61, $121.73,118.03,115.12 \mathrm{ppm}$ respectively, and the $\mathrm{CH}_{2}$ carbon at $48.9 \mathrm{ppm}$.

In the ${ }^{1} \mathrm{H}$ NMR spectrum of 4 (Figure S5), it is rather difficult to even identify aromatic protons of phthalocyanine groups because of the large number of protons of substituted o-carborane groups [35]. Therefore, aromatic protons for compound $\mathbf{4}$ are not observed. The $\mathrm{C}-\mathrm{H}$ protons for the $\mathrm{CH}_{2}-\mathrm{O}$ group are observed at $5.72 \mathrm{ppm}$ as a singlet and are in agreement with the structure shown in Scheme 1.

Phthalocyanine complexes are expected to have positional isomers due to the presence of a single substituent on either the peripheral or non-peripheral positions. Fewer or more positional isomers are expected for the non-peripherally or peripherally substituted complexes due to steric effects. This situation is effective on NMR spectra. Dioxy-o-carborane, substituted complex 4 which is at the peripheral position, hampered the vibrations of Pc ring proton and in the NMR spectrum [36].

Compound 4 is diamagnetic because no cobalt traces were observed at $100 \mathrm{~K}$ in the EPR spectrum. This is also supported by the magnetic susceptibility and NMR measurements. The results presented here suggest that efforts to Ball-type Cobalt phthalocyanine systems should focus on magnetic property.

The positive ion and linear mode MALDI-MS spectrum of compound 3 is presented in Figure S6, and the expected value of the protonated molecular ion at $\mathrm{m} / z 457$ (calc. $\mathrm{m} / z$ 456.519) was confirmed. Only the 2,5-dihyroxybenzoic acid MALDI matrix yielded an intense molecular ion signal.

Co-Pc 4 was synthesized in low yield and demonstrated solubility in dimethyl sulfoxide (DMSO). The melting point of 4 was found to exceed $200{ }^{\circ} \mathrm{C}$. Characterization 


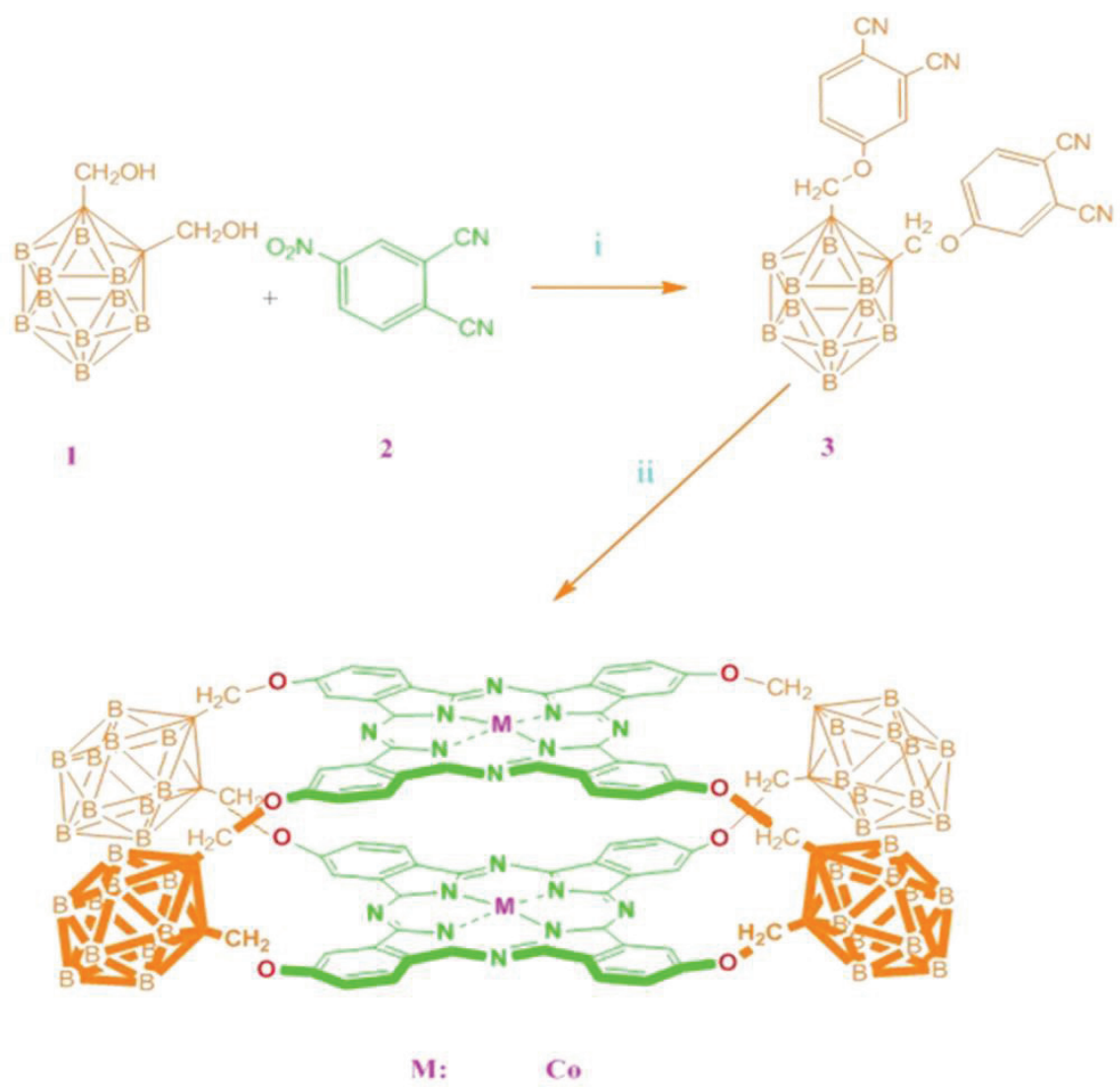

Scheme 1 Synthesis of the phthalocyanine complex: (i) $\mathrm{Cs}_{2} \mathrm{CO}_{3}, \mathrm{~N}_{2}, \mathrm{ACN}, 80^{\circ} \mathrm{C}, 72 \mathrm{~h}$, (ii) $\mathrm{Co}(\mathrm{OAC})_{2} \cdot 6 \mathrm{H}_{2} \mathrm{O}, 300^{\circ} \mathrm{C}, \mathrm{DMAE}, \mathrm{N}_{2}, 24 \mathrm{~h}$.

was achieved using a combination of methods including elemental analysis, FT-IR spectroscopy (Figure S2), ${ }^{1} \mathrm{H}-\mathrm{NMR}$ spectroscopy (Figure S5), UV-Vis spectroscopy (Figure 1) and MALDI-TOF mass spectroscopy (Figure S7).

The positive ion and linear mode MALDI-MS spectrum of the synthesized Co-Pc complex are presented in Figure S7. Several novel MALDI matrices were tested to obtain the molecular ion peak, and 1,8-dihydroxy-9(10H)-anthracenone (Dithranol) yielded the best MALDI-MS spectrum. Beside the protonated molecular ion peak of the complex that was observed at $1945 \mathrm{Da}$, a few low-intensity fragment ions were observed at masses between 900 and 1400 Da. The other peaks at around 600 Da represent the various clusters of MALDI matrix Dithranol used in this study. The complex depicted low fragmentation under linear MALDIMS conditions. The isotopic distribution of the experimental molecular ion overlapped the theoretical isotopic peak pattern for this complex (Figure S7). The combined results indicate that the corresponding metallophthalocyanine was synthesized in the desired manner.

Electronic spectra are very important to verify the structure of phthalocyanine compounds. Phthalocyanines show typical UV-Vis spectra with two absorption regions, the $\mathrm{Q}$ band around $600-700 \mathrm{~nm}$ and the $\mathrm{B}$ band in the near UV region around $300-400 \mathrm{~nm}$. The $\mathrm{Q}$ band of all the compounds are attributed to the $\pi \rightarrow \pi^{\star}$ transition from the highest occupied molecular orbital (HOMO) to the lowest unoccupied molecular orbital (LUMO) of the phthalocyanine ring. B band of all the phthalocyanines arise from the deeper $\pi$ levels / LUMO transitions. The split form of $Q$ band for $\mathbf{2}$, is a characteristic for metal-free phthalocyanines [36].

The ball-type metallophthalocyanine 4, in DMSO, had a typical UV-Vis spectra which demonstrated the expected absorption bands for phthalocyanines (with a Soret band centered at $310 \mathrm{~nm}$ ) and Q-bands at 612 and $673 \mathrm{~nm}$, respectively; both Q-band values were in good agreement with the literature relative to the absorption properties of tetrasubstituted phthalocyanines [37]. The energy band gap $\left(\mathrm{E}_{\mathrm{g}}\right)$ is calculated using the following equation,

$$
\text { Egap }=1239 / \lambda
$$

The extrapolation of absorption spectra towards horizontal axis (wavelength) is $720 \mathrm{~nm}$ (Figure 1). Accordingly, the energy band gap $\left(\mathrm{E}_{\mathrm{g}}\right)$ is $1.72 \mathrm{eV}$ for compound 4 . 


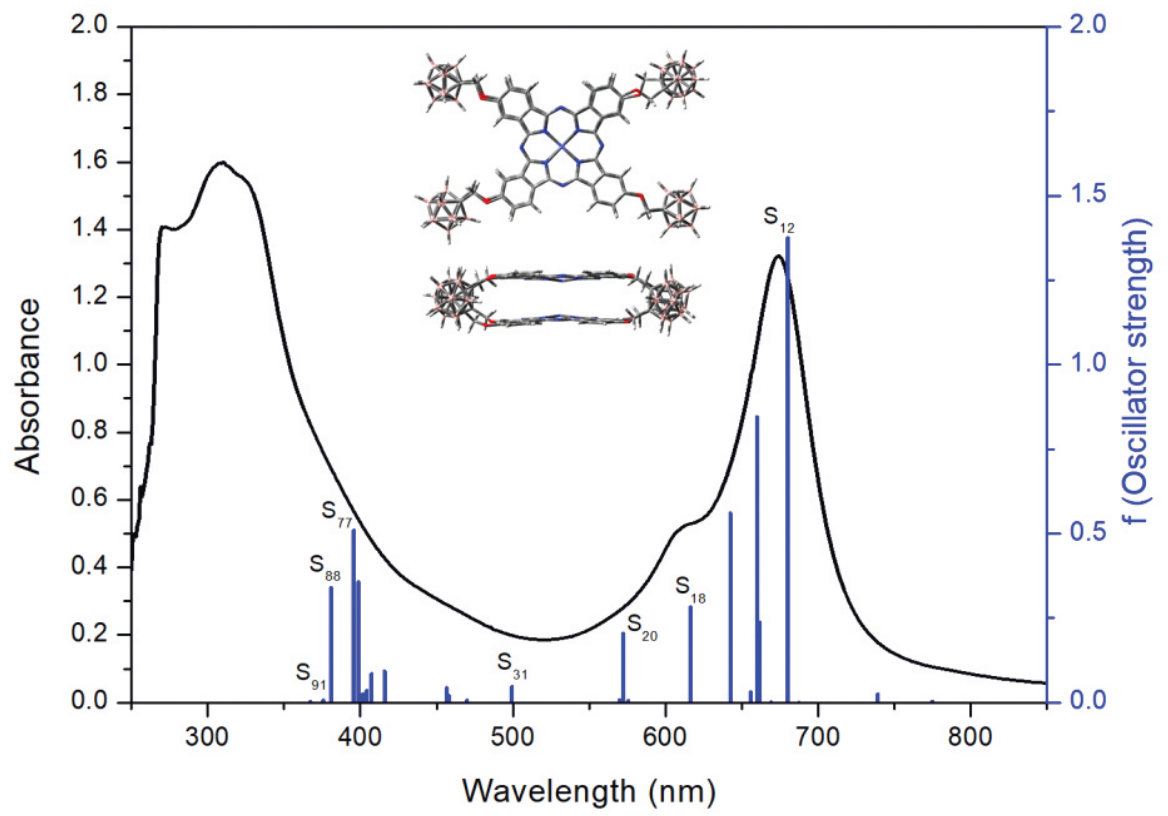

Figure 1 Experimental UV-Vis spectra $\left(1.72 \times 10^{-6} \mathrm{M}\right.$, solid line $)$ and calculated oscillator strengths with TD-DFT method at B3LYP/6$31 \mathrm{G}(\mathrm{d}, \mathrm{p}) /$ LANL2DZ for 4 in DMSO.

This value is very suitable for titanium dioxide applications [38-41]. Figure 1 also displays calculated oscillator strengths. These results are discussed in the DFT calculations section.

\section{Photovoltaic performance}

To record the absorption spectra of the films, $\sim 5-\mu \mathrm{m}$-thick $\mathrm{TiO}_{2}$ films were immersed in DMSO solutions containing Pcs for various time intervals between 12 and $60 \mathrm{~h}$ at $60{ }^{\circ} \mathrm{C}$. The absorption spectra of 4 adsorbed onto the $\sim 5$ - $\mu$ m-thick $\mathrm{TiO}_{2}$ electrodes were very similar to the insolution spectra. A small red shift was observed with much broader bands. This may be due to the aggregation of dyes on the $\mathrm{TiO}_{2}$ surface. Furthermore, light scattering and re-absorption from the nanoparticle surface of $\mathrm{TiO}_{2}$ may cause significant broadening of the spectra.

The main performance for a DSSC are determined using standard test conditions under specific illumination based on four main parameters: short circuit current density $\left(\mathrm{J}_{\mathrm{sc}}\right)$, open-circuit voltage $\left(\mathrm{V}_{\mathrm{oc}}\right)$, fill factor $(\mathrm{FF})$ and photovoltaic conversion efficiency ( $\eta$ ) [42]. FF defines the maximum power output of the solar cell per unit area divided by the product of $\mathrm{J}_{\mathrm{sc}}$, and $\mathrm{V}_{\mathrm{oc}}$ and can be expressed by equation (1):

$$
\mathrm{FF}=\frac{\mathrm{J}_{\text {max }} \times \mathrm{V}_{\text {max }}}{\mathrm{J}_{\mathrm{sc}} \times \mathrm{V}_{\text {oc }}}
$$

$\mathrm{J}_{\max }$ and $\mathrm{V}_{\max }$ are the current and voltage at the point on the $\mathrm{J}-\mathrm{V}$ curve where the maximum power density is delivered by the cell. The photovoltaic conversion efficiency $(\eta)$ is defined as the ratio of the maximum electrical power output of the photovoltaic cell to the energy of the incident sunlight $\left(\mathrm{P}_{\text {in }}\right)$ and can be defined with the formula given in equation (2):

$$
\eta=\frac{\mathrm{V}_{\text {oc }} \times \mathrm{J}_{\text {sc }} \times \mathrm{FF}}{\mathrm{P}_{\text {in }}}
$$

The fabricated cells were characterized by measuring the current density as a function of the applied voltage in ambient air when subjected to an illumination of 100 $\mathrm{mW} \mathrm{cm}{ }^{-2}$. The resulting J-V curve of the DSSCs based on 4 after $36 \mathrm{~h}$ of sensitization is presented in Figure 2 and the device performance parameters are provided in Table 1.

One of our primary objectives was to investigate the effect of sensitization time on the photovoltaic performance of the 4-sensitized DSSCs. To obtain more insight into the effect of sensitization time on the solar cell parameters, DSSC devices were fabricated with various sensitization times, between 12 to $60 \mathrm{~h}$. A comparison of the J-V curves of these DSSC devices is given in Figure 2 and the performance parameters at AM $1.5 \mathrm{G}$ sunlight are listed in Table 1.

As it is clear from Table 1, the DSSC for compound 4 exhibits good photovoltaic properties $\left(V_{o c}\right.$ of $0.80 \mathrm{~V}, J_{s c}$ of $5.41 \mathrm{~mA} \mathrm{~cm}^{-2}$, FF of 0.79 and $\eta$ of $3.42 \%$ under AM $1.5 \mathrm{G}$ 


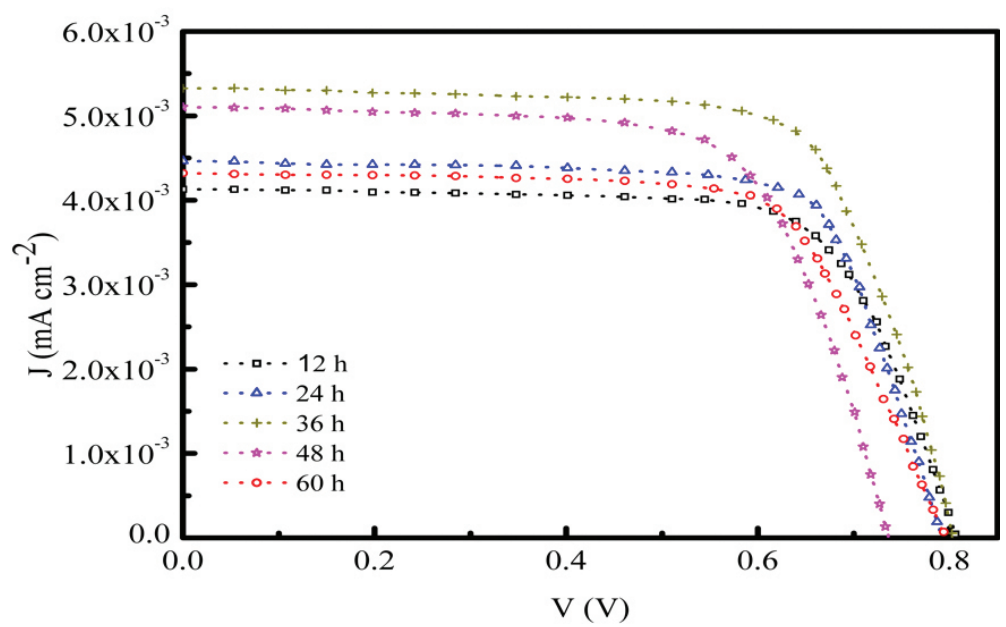

Figure 2 J-V characteristics of DSSCs sensitized with $\mathbf{4}$ at room temperature for different adsorption times.

Table 1 Photovoltaic parameters of DSSCs sensitized with 4 for different sensitization times

\begin{tabular}{lcccccc}
\hline $\begin{array}{l}\text { Sensitization } \\
\text { time (h) }\end{array}$ & $\begin{array}{c}\mathrm{J}_{\mathrm{sc}}(\mathrm{mA} \\
\left.\mathrm{cm}^{-2}\right)\end{array}$ & $\begin{array}{c}\mathbf{V}_{\text {oc }} \\
(\mathrm{V})\end{array}$ & $\begin{array}{c}\mathrm{J}_{\max }(\mathrm{mA} \\
\left.\mathrm{cm}^{-2}\right)\end{array}$ & $\begin{array}{c}\mathbf{V}_{\max } \\
(\mathrm{V})\end{array}$ & FF & $\eta(\%)$ \\
\hline 12 & 4.13 & 0.81 & 3.75 & 0.64 & 0.72 & 2.4 \\
24 & 4.47 & 0.79 & 4.07 & 0.65 & 0.74 & 2.62 \\
36 & 5.41 & 0.80 & 5.52 & 0.62 & 0.79 & 3.42 \\
48 & 5.10 & 0.74 & 4.51 & 0.57 & 0.69 & 2.58 \\
60 & 4.32 & 0.80 & 3.90 & 0.62 & 0.70 & 2.42 \\
\hline
\end{tabular}

irradiation) which are much better than polypyriylruthenium complex photovoltaic properties [32] ( $V_{o c}$ of $0.72 \mathrm{~V}, J_{s c}$ of $20.5 \mathrm{~mA} \mathrm{~cm}^{-2}$, FF of 0.7 and $\eta$ of 0.1 under AM $1.5 \mathrm{G}$ solar irradiance $1000 \mathrm{Wm}^{-2}$ ).

Analysis of the performance parameters (Table 1) shows that $V_{o c}$ is relatively insensitive to sensitization time. $V_{o c}$, which can be considered as the point where the photocurrent generation and dark current processes compensate for each other, is reportedly determined by the Fermi level of the electrons and the electrolyte redox potential [53]. When the same electrolyte is used, the $V_{o c}$ can be expressed as follows [44]:

$$
\mathrm{V}_{\mathrm{oc}}=\frac{\mathrm{E}_{\mathrm{cb}}}{\mathrm{q}}+\alpha \frac{\mathrm{kT}}{\mathrm{q}} \ln \left(\frac{\mathrm{N}_{\mathrm{c}}}{\mathrm{n}}\right)
$$

where $\mathrm{E}_{\mathrm{cb}}$ is the potential that is observed at the conduction band edge, $\alpha$ shows a characteristic constant of the tailing states of $\mathrm{TiO}_{2}$ (k: the Boltzmann constant; $\mathrm{T}$ : temperature, $\mathrm{N}_{\mathrm{c}}$ : the effective density of the states at the $\mathrm{TiO}_{2}$ conduction band edge, and $\mathrm{n}$ : electron number in $\mathrm{TiO}_{2}$ ).
It is clear from Equation (3) that the observed $V_{o c}$ at a given constant voltage strongly depends on the potential of the $E_{c b}$ and the number of electrons injected from the metal-oxide. This means that the values of $\mathrm{E}_{\mathrm{cb}}$ and $\mathrm{n}$ are the limiting factors for achieving a high $V_{o c}$ (Note that the $\mathrm{E}_{\mathrm{cb}}$ and the number of the injected electrons are correlated to the surface charge and charge recombination rate, respectively). Under a steady-state illumination condition, the number of electrons transferred into the conduction band of $\mathrm{TiO}_{2}$ was expected to increase with increasing sensitization time because more dye was expected to adsorb onto the $\mathrm{TiO}_{2}$ film. However, it is formerly determined that $\eta$ strongly depends on the balance between injected electrons and charge recombination. Furthermore, recombination processes are known to cause a decrease in the charge-carrier population and $V_{o c}$. Therefore, the $V_{o c}$ in 4-sensitized DSSC devices is limited by the recombination processes.

One of the performance parameters for a solar cell is the $J_{s c}$. To realize current generation in a DSSC device, three basic processes should be considered: adsorption of incident light by dye molecules, charge collection by the electrodes, and the dye regeneration process. Combination of these three processes may cause the short circuit current for a photovoltaic device. An efficient exciton dissociation occurs when the lowest unoccupied molecular orbital (LUMO) of the photosensitizer is observed to be more negative than the conduction band of the semiconductor $\left(\mathrm{TiO}_{2}\right)$ and when the highest occupied molecular orbital (HOMO) is observed to be more positive than the redox potential of the electrolyte [45]. The observed $J_{s c}$ increased with increasing dye-sensitization time with the maximum $\mathrm{t}_{\max }$ ) at $36 \mathrm{~h}$ (Table 1). Thereafter, the $J_{s c}$ decreased. The same measurements were then repeated 
for another 4-sensitized DSSC device taken from the same batch of samples to verify the repeatability of the observed sensitization time-dependence. These measurements verified that the observed J-V behaviours were repeatable, except for a small shift in the $V_{o c}$. In this respect, the low $J_{s c}$ in a 4-based device can be attributed to recombination of injected electrons either radiatively or non-radiatively. The increase in short circuit current with increasing sensitization time can be attributed to the decrease in chargetransfer resistance at the interface, which facilitates transport of the injected electrons in the photoanode layer and affords improved short circuit current. The maximum $\mathrm{J}_{\text {sc }}$ value and conversion efficiency of the solar cell could be found after sensitization for $36 \mathrm{~h}$ suggests that monolayer dye adsorption on the $\mathrm{TiO}_{2}$ film was nearly complete after this duration. The gradual reduction in $\mathrm{J}_{\mathrm{sc}}$ value and conversion efficiency could be ascribed by the multilayer formation or dye aggregation. The decrease in $\mathrm{J}_{\mathrm{sc}}$ value can be explained by the contribution of the multilayer formation to the series resistance increase. Also, Polypyridylruthenium complexes are reported to be the most successful sensitizers and their absorption wavelengths are in the range of 570-600 $\mathrm{nm}[28,32]$. In this study, the absorption wavelength of the synthesized Co-Pc complex was observed to be in the range of $612-673 \mathrm{~nm}$. This can be explained as a result of the decrease in $\mathrm{J}_{\mathrm{sc}}$. For a related dye, $\mathrm{ZnPc}$, it has been reported that dye aggregation led to self-quenching enhancements of the excited singlet state [46].

\section{DFT Studies}

Spartan08 [47], Gaussian09 [48] and Gaussview5.0 [49] software packages were used in the calculations. The DFT approach was used to optimize ground state geometries [50]. Calculations were carried out using Becke's threeparameter nonlocal exchange functional [51,52] with the Lee-Yang-Parr correlation function [53] (hybrid B3LYP functional) for DFT and TDDFT with $6-31 \mathrm{G}(\mathrm{d}, \mathrm{p})$ and LANL2DZ (for metal) basis sets [54-57]. The ground-state structure of $\mathbf{4}$ was optimized in DMSO and the minima were verified with positive calculated frequencies (Figure S8). Solvent effects were investigated using the Polarizable Continuum Model (PCM) $[58,59]$ in ground state as implemented in Gaussian09.

The dipole moment $(\mu)$, sum of electronic and zeropoint energies $\left(\mathrm{E}_{\text {elec }}+\mathrm{ZPE}\right)$, and sum of electronic energy and thermal free energy $\left(\mathrm{E}_{\text {elec }}+\Delta \mathrm{G}\right)$ were calculated to be 4.44 Debye, -5857.9572 Hartree, and -5858.0852 Hartree, respectively. The first frequency was found at $8.12 \mathrm{~cm}^{-1}$. As expected, 4 has a peripheral structure. The closest distance was observed between the two central Co atoms (3.03 $\AA$ ), and the distance between Co and the Pc N atoms was nearly 3.63 A.

Experimental and calculated UV-Vis absorption spectra were found in agreement in DMSO (Figure 1). The first 100 singlet states were calculated to analyse the electronic transitions and Table S1 shows the list of selected transitions of compound 4. Maximum peak at longer wavelength appears at $680 \mathrm{~nm}$ and it belongs to the local excitation of the Pc core (LE1). At longer wavelengths of electronic transitions, shifts to IR region are observed. At shorter wavelengths $(616.5 \mathrm{~nm}, 499.3 \mathrm{~nm})$, UV spectrum displays ligand-to-metal charge transition (LMCT) character and d-d transition (LE2) is observed between metal d orbitals at $572 \mathrm{~nm}$. Additionally, intramolecular charge transfer (ICT) is observed on the bridging oxygen atoms between carborane groups and Pcs towards Pc core in many electronic transitions.

\section{Experimental}

\section{Materials}

All the initial materials and solvents were high purity commercial products that were obtained from Merck or Aldrich and were used as supplied unless otherwise pointed. Commercial 1,2-bis(2-hydroxymethyl)-O-carborane (HMOC) (1) was purchased from Katchem. 4-nitrophthalonitrile (2) was purchased from Sigma Aldrich. All the reactions were performed under a dinitrogen atmosphere.

\section{Characterization techniques}

Microanalyses were performed using a CHNS-932 (LECO) elemental analyzer. The ${ }^{1} \mathrm{H}$-NMR and ${ }^{13} \mathrm{C}$-NMR were measured on Varian Innova $600 \mathrm{MHz}$ spectrometer. Chemical shift values for ${ }^{1} \mathrm{H}-\mathrm{NMR}$ and ${ }^{13} \mathrm{C}$-NMR were referenced relative to $\mathrm{Si}\left(\mathrm{CH}_{3}\right)_{4}$. The UV-Vis spectra were recorded using a Perkin Elmer lambda 35 spectrophotometer with $1-\mathrm{cm}$ quartz cuvettes at room temperature. The IR spectra were obtained in the form of $\mathrm{KBr}$ pellets on a Perkin Elmer Spectrum FT-IR spectrophotometer. Mass spectra were obtained in linear mode with an average of 100 shots on a Voyager-DE ${ }^{\mathrm{TM}}$ Pro MALDI-TOF mass spectrometer (Applied Biosystems, USA) that was combined with a nitrogen UV-laser (337 nm). The MALDI matrix, 1,8-dihydroxy$9(10 \mathrm{H})$-anthracenone (dithranol), was prepared in tetrahydrofuran at a concentration of $10 \mathrm{mg} \mathrm{mL}^{-1}$. The MALDI sample was prepared by combining sample solutions (1.5 
$\mathrm{mg} \mathrm{mL} \mathrm{m}^{-1}$ in dimethyl sulfoxide (DMSO) with the matrix solution (1:10 v/v) in a $0.5 \mathrm{~mL}$ Eppendorf ${ }^{\circledast}$ micro tube, and $1.0 \mu \mathrm{L}$ of this mixture was deposited on the sample plate, dried at room temperature, and then analyzed. JEOL JesFa300 X-band EPR spectrometer was used for EPR measurements. The magnetic susceptibility measurements were made with the Sherwood Scientific MX1 model Gouy magnetic susceptibility scale.

\section{Chemical synthesis}

\section{Synthesis [\{bis(2-oxymethyl-4-phthalonitrile)\} 0 -carborane] (3)}

Finely ground anhydrous $\mathrm{Cs}_{2} \mathrm{CO}_{3}(2.0 \mathrm{~g}, 15.0 \mathrm{~mol})$ was added to 1,2-bis(2-hydroxymethyl)- $\mathrm{O}$-carborane (HMOC) 1 (0.204 g, 1mol) and 4-nitrophthalonitrile $2(0.346 \mathrm{~g}, 2$ $\mathrm{mol})$ in a solution of acetonitrile $(25 \mathrm{ml})$, and the mixture was magnetically stirred at reflux for $72 \mathrm{~h}$ under a dry $\mathrm{N}_{2}$ atmosphere at $85{ }^{\circ} \mathrm{C}$. After cooling to room temperature, the reaction mixture was filtered to eliminate the undissolved salt; further, the filtrate was evaporated to dryness to produce an oily residue. Compound $\mathbf{3}$ was precipitated using petroleum ether $(30 \mathrm{~mL})$ and was collected. This compound was washed with plenty of petroleum ether and tetrahydrofuran successively and air-dried. Compound 3 was readily soluble in acetone.

The Compound 3 was obtained in $62 \%$ ( $286 \mathrm{mg}$ ) yield as a yellow color; ${ }^{1} \mathrm{H}$ NMR $\left(600 \mathrm{MHz}, d_{6}-\right.$ acetone, $25^{\circ} \mathrm{C}$, $\left.\mathrm{Si}\left(\mathrm{CH}_{3}\right)_{4}\right)$ 8/ppm: 8.95 (s, $\left.1 \mathrm{H} ; \mathrm{Ar}-\mathrm{H}\right), 8.77$ (d, $\left.1 \mathrm{H}, \mathrm{Ar}-\mathrm{H}\right)$; $8.45(\mathrm{~d}, 1 \mathrm{H}, \mathrm{Ar}-\mathrm{H}), 3.11$ (s, 4H; $\left.\mathrm{CH}_{2}-\mathrm{H}\right) ;{ }^{13} \mathrm{C}$ NMR $(600 \mathrm{MHz}$, $d_{6}$ - acetone, $\left.25{ }^{\circ} \mathrm{C}, \mathrm{Si}\left(\mathrm{CH}_{3}\right)_{4}\right)$ 8/ppm 136.47, 129.61, 121.73 ( $\mathrm{Ar}-\mathrm{C}), 118.03,115.12(\mathrm{Ar}-\mathrm{CN})$ and $48.9\left(\mathrm{O}-\mathrm{CH}_{2}\right)$; IR $(\mathrm{KBr}$ pellets) $\mathrm{v}^{-1} / \mathrm{cm}^{-1}: 2969$ (Ar-CH), 2533 and 2366 (Ar-BH), $2225(\mathrm{Ar}-\mathrm{C} \equiv \mathrm{N}), 1596$ and $1496(\mathrm{Ar}-\mathrm{C}=\mathrm{C}), 1347$ and 1256 (Ar-C-N), 1099 (C-O-C); m.p.: $146-153^{\circ} \mathrm{C}$; Anal. Calcd for compound $3\left[\mathrm{C}_{20} \mathrm{H}_{20} \mathrm{O}_{2} \mathrm{~N}_{4} \mathrm{~B}_{10}\right](\mathrm{M}=456.52)$ are $\mathrm{C} 52.57, \mathrm{H} 4.38$, N 12.27; found: C 53.07, H 4.92, N 12.4; MS m/z: 456.52 ( M+, $100 \%)$ and $457(\mathrm{M}+\mathrm{H})^{+}$.

\section{[2',10',16',24'-tetrakis\{bis(2-oxymethyl-4-phenyl-0- carborane)\}bisphthalocyaninato-dicobalt] (4)}

A mixture of $3(0.182 \mathrm{~g}, 0.4 \mathrm{mmol})$ and $\mathrm{Co}(\mathrm{OAc})_{2} \cdot 6 \mathrm{H}_{2} \mathrm{O}$ $(0.01 \mathrm{~g}, 0.2 \mathrm{mmol})$ was dissolved in dimethylaminoethanol (DMAE) under a dry $\mathrm{N}_{2}$ atmosphere in a sealed glass tube and was heated for $24 \mathrm{~h}$ at $300{ }^{\circ} \mathrm{C}$. After reaching room temperature, the dark-green mixture was washed with distilled water to eliminate the excess cobalt acetate and was further filtered and washed repeatedly using hot water and different solvents (ethanol, chloroform, and diethyl ether) before drying under vacuum at $70^{\circ} \mathrm{C}$. Compound 4 was soluble in DMSO.

The Compound 4 was obtained in $4 \%(66 \mathrm{mg})$ yield as a yellow color; ${ }^{1} \mathrm{H}-\mathrm{NMR}\left(600 \mathrm{MHz}, d_{6}-\mathrm{DMSO}, 25^{\circ} \mathrm{C}\right.$, $\left.\mathrm{Si}\left(\mathrm{CH}_{3}\right)_{4}\right) \delta / \mathrm{ppm}: 5.72\left(\mathrm{~s}, 4 \mathrm{H}, \mathrm{CH}_{2}-\mathrm{H}\right)$; UV (DMSO) $\lambda_{\max } /$ $\mathrm{nm}:$ 310, 612 and $673\left(\log \varepsilon / \mathrm{M}^{-1} \mathrm{~cm}^{-1}\right.$ :5.97, 5.48 and 5.88); IR (KBr pellets) $v^{-1} / \mathrm{cm}^{-1}: 3828,3436\left(\mathrm{H}_{2} \mathrm{O}\right), 2924$ and 2857 (Ar-CH), 2539 and $2366(\mathrm{Ar}-\mathrm{B}-\mathrm{H}), 1611(\mathrm{Ar}-\mathrm{C}=\mathrm{N}), 1465$ $(\mathrm{Ar}-\mathrm{C}=\mathrm{C}), 1390(\mathrm{Ar}-\mathrm{C}-\mathrm{N}), 1239(\mathrm{Ar}-\mathrm{C}=\mathrm{N}), 1095(\mathrm{C}-\mathrm{O}-\mathrm{C})$; $\mu_{\text {eff }}(\mathrm{BM})$ : Diamagnetic; m.p.: $>250^{\circ} \mathrm{C}$; Anal. Calcd for compound $4\left[\mathrm{C}_{80} \mathrm{H}_{80} \mathrm{~B}_{40} \mathrm{Co}_{2} \mathrm{~N}_{16} \mathrm{O}_{8}\right](\mathrm{M}=1943.98)$ are $\mathrm{C} 49.38, \mathrm{H}$ 4.12, N 11.52; found: C 50.2, H 4.4, N 11.98; MS m/z : 1943.98 $(\mathrm{M}+, 100 \%)$, and $1945(\mathrm{M}+\mathrm{H})$.

\section{DSSC fabrication and characterization}

DSSCs were produced using fluorine-doped tin oxide (FTO)-coated glass substrates. Before coating the nanoporous $\mathrm{TiO}_{2}$ paste onto the FTO substrates, the FTO substrates were cleaned as follows: First, ultrasonic treatment for $40 \mathrm{~min}$ in a detergent solution; second, ultrasonic bath treatment for 15 min in deionized (DI) water; third, ultrasonic bath treatment in isopropyl alcohol for $15 \mathrm{~min}$; and fourth, drying under flowing dry nitrogen. The porous $\mathrm{TiO}_{2}$ layer was prepared by applying a paste of $\mathrm{TiO}_{2}$ nanoparticles onto the FTO glass substrates using a surgical blade and was annealed at $450{ }^{\circ} \mathrm{C}$ in air for $30 \mathrm{~min}$. The annealed substrates were allowed to reach $60^{\circ} \mathrm{C}$ and were further dipped into the dye solution. The $\mathrm{TiO}_{2}$ electrodes were immediately immersed in a $0.4 \mathrm{mM}$ solution of 4 in DMSO (dye solution) for various immersion times between 12 and $60 \mathrm{~h}$. On completion of dye sensitization, the photoanodes were removed from the dye solution, washed thoroughly with DMSO to eliminate the non-adsorbed dye molecules, and dried under a stream of high-purity nitrogen. The 4-sensitized $\mathrm{TiO}_{2}$ photo-anodes and thermally platinum-plated counter electrode were assembled into a sealed sandwich-type cell using the gap of a hot-melt ionomer film. An iodide-based electrolyte containing $0.6 \mathrm{M}$ 1-butyl-3-methylimidazolium iodide (BMII), 0.3 M lithium iodide, $0.07 \mathrm{M}$ iodine, and $0.6 \mathrm{M}$ tert-butylpyridine in a mixture of acetonitrile:valeronitrile (80:20) was used. The devices were characterized by means of current-voltage (I-V) measurements using a Keithley 6517 A electrometer under solar simulator illumination $\left(100 \mathrm{~mW} \mathrm{~cm}^{-2}\right.$ irradiance, AM 1.5 G). The diode parameters of fabricated $\mathrm{n} \mathrm{SnS}_{2}$ /p-Si were measured under illumination with a Xenon lamp(150 W short-area) equipped portable solar simulator 
(PEC-L01).The conversion efficiency ( $\eta$ ) and the fill factor (FF) of the prepared DSSCs were estimated using the measured I-V characteristics.

\section{Conclusions}

A novel ball-type Co-containing metallophthalocyanine with peripheral carborane units was successfully synthesized. The synthesized compounds were structurally and electronically characterized using elemental analysis, UV-Vis spectroscopy, FT-IR spectroscopy, ${ }^{1} \mathrm{H}-\mathrm{NMR}$ spectroscopy, MALDI-TOF mass spectrometry, EPR spectroscopy, and magnetic susceptibility. Additionally, calculated UV-Vis absorption spectra of the molecule were compared with experimental spectra and found in agreement with each other. The newly synthesized phthalocyanine 4 was combined with anatase $\mathrm{TiO}_{2}$ nanoparticle films to construct a working dye-sensitized solar cell. The performance of the resulting photovoltaic cells (photovoltaic conversion efficiency, short circuit current, and fill factor) was highly dependent on the dye-sensitization time. The photocurrent of $\mathbf{4}$ increased with sensitization time up to $36 \mathrm{~h}$ (short circuit current density, $5.41 \mathrm{~mA} \mathrm{~cm} \mathrm{~cm}^{-2}$; overall conversion efficiency, 3.42\%) and then decreased with prolonged dye-sensitization time.

Acknowledgements: I gratefully acknowledge the financial support for Ayşe Ilgan Necipoğlu. I also thank Prof. Dr. Özer Bekaroğlu, Prof. Dr. Bekir Salih, Prof. Dr. Ahmet Altındal, Associate Prof. Dr. Nursel Acar Selçuki, Prof Dr. Recep Tapramaz, Prof. Dr. Ülkü Sayın, Prof. Dr. Okan Zafer Yeşilel, and Prof. Dr. Cenk Selçuki for their support during my study.

Conflicts of Interest: The author declares no conflict of interest.

\section{References}

[1] McKeown NB. Phthalocyanine Materials: Synthesis, Structure and Function. London: Cambridge University Press; 1998.

[2] Simon J, Bassoul P. Design of Molecular Materials: Supramolecular Engineering. Newyork: Wiley-VCH; 2001.

[3] Torre G, Vázquez P, Agulló-López F, Torres T. Role of Structural Factors in the Nonlinear Optical Properties of Phthalocyanines and Related Compounds. Chem Rev. 2004;104:3723-50.

[4] Eichhorn H, Wohrle D, Pressner D. Glasses of new 2,3,9,10,16,17,23,24-octasubstituted phthalocyanines forming thermotropic and lyotropic discotic mesophases. Liq Cryst. 1997;22:643-53.
[5] Wright JD, Roisin P, Rigby GP, Nolte RJ, Cook MJ, Thorpe SC. Crowned and liquid-crystalline phthalocyanines as gas-sensor materials. Sens Actuators B Chem. 1993;13:276-80.

[6] Zhou R, Josse F, Göpel W, Öztürk ZZ, Bekaroğlu Ö. Phthalocyanines as Sensitive Materials for Chemical Sensors. Appl Organomet Chem. 1996;10:557-77.

[7] Lukas B, Silver J. Lovett Dr, Cook M). Electrochromism in the octapentyloxy nickel phthalocyanines and related phthalocyanines. Chem Phys Lett. 1995;241:351-4.

[8] Bekaroglu Ö. Phthalocyanines Containing Macrocycles. Appl Organomet Chem. 1996;10:605-22.

[9] Nevin WA, Hempstead MR, Liu W, Leznoff CC, Lever AB. Electrochemistry and spectroelectrochemistry of mononuclear and binuclear cobalt phthalocyanines. Inorg Chem. 1987;26:570-7.

[10] Mas-Torrent M, Rovira C. Role of Molecular Order and Solid-State Structure in Organic Field-Effect Transistors. Chem Rev. 2011;111:4833-56.

[11] Tolbin AY, Ivanov AV, Tomilova LG, Zefirov NS. Preparation of 1,2-bis(3,4-dicyanophenoxymethyl)benzene and the binuclear zinc phthalocyanine derived from it. Mendeleev Commun. 2002;12:96-7.

[12] Tolbin AY, Ivanov AV, Tomilova LG, Zefirov NS. Synthesis of 1,2-bis(3,4-dicyanophenoxymethyl)benzene and binuclear zinc phthalocyanines of clamshell and ball types. J. Porphyr. Phthal. 2003;7:162-6.

[13] Bekaroğlu Ö. Structural Bond; Functional Phthalocyanine Molecular Materials. Berlin, Heidelberg: Springer-Verlag; 2010.

[14] Grimes RN. Carboranes. 3rd ed. Elsevier; 2016.

[15] Bregadze VI, Sivaev IB, Gabel D, Whorle DJ. Polyhedral boron derivatives of porphyrins and phthalocyanines. J of Porphyr Phthal. 2001;5:767-81.

[16] Wu SH. Jones JrM. The mechanism of rearrangement of the icosahedral carboranes. J Am Chem Soc. 1989;111:5373-84.

[17] Mayes N, Greene J, Cohen MS. Carborane polymers IV. Polysiloxanes. J. Polym. Sci. Part A. Polymer Chemistry. 1967;5:365-79.

[18] Papetti S, Schaeffer BB, Grey AP, Heying TL. A new series of organoboranes. VII. The preparation of poly-m-carboranylenesiloxanes. J Polym Sci A. 1966;4:1623.

[19] Brown DA, Colquhoun HM, Daniels JA, MacBride JA, Stephenson IR, Wade K. Polymers and ceramics based on icosahedral carboranes. Model studies of the formation and hydrolytic stability of aryl ether, ketone, amide and borane linkages between carborane units. J Mater Chem. 1992;2:793-804.

[20] Paxton RJ, Beatty BG, Hawthorne MF, Varadarajan A, Williams LE, Curtis FL, et al. A transation metal complexes (Venus flytrap cluster) for radioimmunodetection and radioimmunotherapy. Proc Natl Acad Sci USA. 1991;88:3387-91.

[21] Shelly K, Feakes DA, Hawthorne MF, Schmidt PG, Krish TA, Bauer WF. Model studies directed toward the boron neutroncapture therapy of cancer: boron delivery to murine tumors with liposomes. Proc Natl Acad Sci USA. 1992;89:9039-43.

[22] Hawthorne MF. Biochemical applications of boron cluster chemistry. Pure Appl Chem. 1991;63:327-34.

[23] Hawthorne MF. The Role of Chemistry in the Development of Boron Neutron Capture Therapy of Cancer. Angew Chem. 1993;32:950-84. 
[24] Hawthorne MF, Maderna A. Applications of radiolabeled boron clusters to the diagnosis and treatment of cancer. Chem Rev. 1999;99:3421-34.

[25] Douglass AG, Czuprynski K, Mierzwa M, Kaszynski P. An assessment of carborane-containing liquid crystals for potential device application. J Mater Chem. 1998;8:2391-8.

[26] Grimes RN. Boron Clusters Come of Age. J Chem Educ. 2004;81:658-72.

[27] Andrews PC, Atwood JL, Barbour LJ, Croucher PD, Nichols PJ, Smith BW, et al. Supramolecular confinement of $\mathrm{C} 60$, S8, P4Se3 and toluene by metal(II) macrocyclic complexes. J Chem Soc, Dalton Trans. 1999;17:2927-32.

[28] O’Regan B, Grätzel M. A low-cost, high-efficiency solar cell based on dye-sensitized colloidal TiO2 films. Nature. 1991;353:737-40.

[29] Jin L, Chen D. Enhancement in photovoltaic performance of phthalocyanine-sensitized solar cells by attapulgite nanoparticles. Electrochim Acta. 2012;72:40-5.

[30] Dastan D, Banpurkar A. Solution processable sol-gel derived titania gate dielectric for organic field effect transistors. J Mater Sci Mater Electron. 2017;28:3851-9.

[31] Dastan D, Panahi SL, Chaure NB. Characterization of titania thin films grown by dip-coatingTechnique. J Mater Sci Mater Electron. 2016;27:12291-6.

[32] Nazeeruddin MK, Pechy P, Renouard T, Zakeeruddin SM, Humphry-Baker R, Comte P, et al. Engineering of Efficient Panchromatic Sensitizers for Nanocrystalline TiO2-Based Solar Cells. J Am Chem Soc. 2001;123:1613-24.

[33] Laromaine A, Teixidor F, Kivekäs R, Sillanpää R, Benakki R, Grüner B, et al. Synthesis reactivity and structural studies of carboranyl thioethers and disulfides. Dalton Trans. 2005;10:1785-95.

[34] Wöhrle D, Tsaryova O, Semioshkin A, Gabel D, Suvorova 0. Synthesis and photochemical properties of phthalocyanine zinc (II) complexes containing o-carborane units. J Organomet Chem. 2013;747:98-105.

[35] Birsöz B, Nar I, Gül A. Synthesis, characterization and electrochemical investigation of phthalocyanines carrying 96 boron atoms. J Organomet Chem. 2014;755:64-71.

[36] Tau P, Nyokong T. Sythesis, characterization and electrochemical characterization of $\alpha$ and $\beta$-tetra-substituted oxo (phthalocyaninato) titanium (IV) complexes. Polyhedron. 2006;25(8):1802-10.

[37] Stillman MJ, Nyokong T, Leznoff CC, Lever AB. Phthalocyanines:Properties and Applications. New York: VCH; 1989.

[38] Dastan D, Chaure N, Kartha M. Surfactants assisted solvothermal derived titania nanoparticles: synthesis and simulation. J Mater Sci Mater Electron. 2017;28:7784-96.

[39] Dastan D, Chaure NB. Influence of surfactants on TiO2 nanoparticles grown by Sol-Gel Technique. J. Mater. Mech. Manufact. 2014;2:21-4.

[40] Dastan D, Panahi SL, Yengantiwar A. Morphological and electrical studies of titania powder and films grown by aqueous solution method. Adv Sci Lett. 2016;22:950-3.

[41] Panahi SL, Dastan D, Chaure NB. Characterization of zirconia nanoparticles grown by sol-gel method. Adv Sci Lett. 2016;22:941-4.
[42] Skompska M. Hybrid conjugated polymer/semiconductor photovoltanic cells. Synth Met. 2010;160:1-15.

[43] Alarcón A, Boschloo G, Mendoza P, Solis JL, Hagfeldt A. Dye-Sensitized Solar Cells Based on Nanocrystalline TiO2 Films Surface Treated with Al3+ Ions: Photovoltage and Electron Transport Studies. J Phys Chem B. 2005;109(39):18483-90.

[44] Mikroyannidis JA, Suresh P, Roy MS, Sharma GD. New photosensitizer with phenylenebisthiophene central unit and cyanovinylene 4-nitrophenyl terminal units for dye-sensitized solar cells. Electrochim Acta. 2011;56:5616-23.

[45] Hara K, Sato T, Katoh R, Furube A, Ohga Y, Shinpo A, et al. Molecular design of coumarin dyes for efficient dye-sensitized solar cells. J Phys Chem B. 2003;107:597-606.

[46] Kimura M, Nomoto H, Suzuki H, Ikeuchi T, Matsuzaki H, Murakami TN, et al. Molecular Design Rule of Phthalocyanine Dyes for Highly Efficient Near-IR Performance in Dye-Sensitized Solar Cells. Chemistry. 2013;19:7496-502.

[47] Spartan 08 for Windows. Wavefunction Inc. Irvine, United State, 2008.

[48] Frisch MJ, Trucks GW, Schlegel HB, Scuseria GE, Robb MA, Cheeseman JR, et al. Fox DJ. Wallingford, United States: Gaussian Inc.; 2009.

[49] Dennington R, Keith T, Millam J. Semichem Inc. United States: Shawnee Mission; 2009.

[50] Kohn W, Sham LJ. Self-consistent Equations Including Exchange and Correlation Effects. Phys Rev. 1965;140:A1133.

[51] Becke AD. Density-Functional Exchange-Energy Approximation with Correct Asymptotic Behaviour. Phys Rev A. 1988;38:3098-100.

[52] Becke AD. Density-Functional Thermochemistry III. The Role of Exact Exchange. J Chem Phys. 1993;98:5648.

[53] Lee C, Yang W, Parr RG. Development of the Colle-Salvetti Correlation-Energy Formula into a Functional of the Electron Density. Phys Rev B Condens Matter. 1988;37:785-9.

[54] Dunning THJr (Hay PJ, Schaefer HF, editors). Modern Theoretical Chemistry: Methods of electronic Structure theory. New York: Plenum Press; 1977.

[55] Hay PJ, Wadt WR. Ab initio effective core potentials for molecular calculations - potentials for the transition-metal atoms Sc to Hg. J Chem Phys. 1985;82:270-83.

[56] Wadt WR, Hay PJ. Ab initio effective core potentials for molecular calculations - potentials for main group elements Na to Bi. J Chem Phys. 1985;82:284-98.

[57] Hay PJ, Wadt WR. Ab initio effective core potentials for molecular calculations - potentials for $\mathrm{K}$ to $\mathrm{Au}$ including the outermost core orbitals. J Chem Phys. 1985;82:299-310.

[58] Tomasi J, Mennucci B, Cancès E. The IEF version of the PCM solvation method: an overview of a new method addressed to study molecular solutes at the QM ab initio level. J Mol Struct THEOCHEM. 1999;464:211-26.

[59] Scalmani G, Frisch MJ, Mennucci B, Tomasi J, Cammi R, Barone V. Geometries and properties of excited states in the gas phase and in solution: theory and application of a time-dependent density functional theory polarizable continuum model. J Chem Phys. 2006;124:094107. 